\title{
Modified Mesoporous Silica (SBA-15) with Trithiane as a new effective adsorbent for mercury ions removal from aqueous environment
}

\author{
Mehdi Esmaeili Bidhendi ${ }^{*}$, Gholam Reza Nabi Bidhendi ${ }^{1}$, Nasser Mehrdadi ${ }^{1}$ and Hamid Rashedi
}

\begin{abstract}
Background: Removal of mercury from aqueous environment has been highly regarded in recent years and different methods have been tested for this purpose. One of the most effective ways for mercury ions $\left(\mathrm{Hg}^{+2}\right)$ removal is the use of modified nano porous compounds. Hence, in this work a new physical modification of mesoporous silica (SBA-15) with 1, 3, 5 (Trithiane) as modifier ligand and its application for the removal of $\mathrm{Hg}^{+2}$ from aqueous environment has been investigated. SBA-15 and Trithiane were synthesized and the presence of ligand in the silica framework was demonstrated by FTIR spectrum. The amounts of $\mathrm{Hg}^{+2}$ in the samples were determined by cold vapor generation high resolution continuum source atomic absorption spectroscopy. Also, the effects of $\mathrm{pH}$, stirring time and weight of modified SBA-15 as three major parameters for effective adsorption of $\mathrm{Hg}^{+2}$ were studied.

Results: The important parameter for the modification of the adsorbent was Modification ratio between ligand and adsorbent in solution which was 1.5. The results showed that the best $\mathrm{Hg}^{+2}$ removal condition was achieved at $\mathrm{pH}=5.0$, stirring time $15 \mathrm{~min}$ and $15.0 \mathrm{mg}$ of modified adsorbent. Moreover, the maximum percentage removal of $\mathrm{Hg}^{+2}$ and the capacity of adsorbent were $85 \%$ and $10.6 \mathrm{mg}$ of $\mathrm{Hg}^{+2} / \mathrm{g}$ modified SBA-15, respectively.
\end{abstract}

Conclusions: To sum up, the present investigation introduced a new modified nano porous compound as an efficient adsorbent for removal of $\mathrm{Hg}^{+2}$ from aqueous environment.

Keywords: Mercury, Mesoporous Silica, Adsorbent, Modified, Wastewater, SBA-15, Trithiane

\section{Introduction}

Mercury as a kind of heavy metal is present in industrial wastewater such as chemical industry, mining, refining petrochemical and a wide variety of industrial activities $[1,2]$. This toxic and hazardous chemical compound has harmful effects on the environment and human health. In fact, mercury due to its bioaccumulation property the same as other heavy metals [3], has damaging effects on vital organs such as heart, brain, liver and fatty texture and will result in different cancers. Therefore, this compound is considered as one of the most toxic metals found in the environment and a main source of pollution $[4,5]$. Hence, nowadays mercury ions removal from aqueous environment (water \& wastewater) as one of

\footnotetext{
* Correspondence: Esmaeilib@ut.ac.ir

'Department of Environmental Engineering, Graduate Faculty of Environment, University of Tehran, Tehran, Iran

Full list of author information is available at the end of the article
}

the major challenges for hygienic management of societies has been the subject of extensive technological research [6]. Several methods including solvent extraction chemical precipitation, vacuum evaporation, membrane technologies, ion exchange, adsorption and membrane separation have been developed and used to remove $\mathrm{Hg}^{+2}$ from environment [1,7-10], but some of these methods such as adsorption owing to different problems like low mechanical and thermal stability and a weak chemical union with the $\mathrm{Hg}^{+2}$, are often costly or inefficient for removing $\mathrm{Hg}^{+2}$ from dilute solutions $[1,10,11]$. Thus, the scientific community has felt obliged to look for a new method to remove $\mathrm{Hg}^{+2}$ from the environment [10]. Hence, synthesis and modification of adsorbents for the removal $\mathrm{Hg}^{+2}$ and other heavy metals ions from water and wastewater is a continuing research objective for the control of environmental pollution [12-17]. In this regard, the development of modified mesoporous materials based on 
MCM-41 and SBA-15 [18] because of their great advantages among large surface area, uniform pore size and controlled surface chemistry for adsorption applications including removal and determination of metal ions [19-24], radio nuclides [25], dyes [26], organics [27], and anionic complexes [28,29], has generated considerable interest [30]. According to the abovementioned, SBA-15 as one of the main types of mesoporous silica materials [31] is a highly common material possessing a regular two dimensional hexagonal array of channels [30]. This material is prepared with non-ionic amphiphilic triblock copolymer micelles as the template under acidic reaction conditions [10]. The pore size of this material typically can be varied between 7-10 nm [30], by varying the synthesis temperature (between 30 and $90^{\circ} \mathrm{C}$ ) and the template [10]. Furthermore, a variety of functional groups such as organic ligands can be grafted or incorporated chemically or physically on the surface of mesoporous channels and prepare highly effective and selective adsorbents [32,33]. Therefore, in this research, 1, 3, 5 Trithiane due to its ability to adsorb $\mathrm{Hg}^{+2}$ has been chosen as the ligand for the modification of SBA-15 resulting in a new adsorbent for removing $\mathrm{Hg}^{+2}$ from aqueous environment and the Batch method was applied in order to examine the capability of this new adsorbent.

\section{Materials and methods Reagents and chemicals}

All chemicals and reagents used in this research were of analytical grade purchased from Merck Company (Darmstadt, Germany). Also, doubly distilled deionized water was used throughout for preparing all solutions. A stock solution $\left(1000 \mathrm{mg} \mathrm{L}^{-1}\right)$ of $\mathrm{Hg}^{+2}$ was prepared by dissolving the appropriate amounts of $\mathrm{Hg}\left(\mathrm{NO}_{3}\right)_{2}$ in doubly distilled deionized water and also a stock standard acetate buffer solution with $\mathrm{pH} 5.0$ was prepared by mixing $14.8 \mathrm{~mL} 0.2 \mathrm{M}$ acetic acid with $35.2 \mathrm{~mL} 0.2 \mathrm{M}$ sodium acetate trihydrate and volume with doubly distilled deionized water to $100 \mathrm{~mL}$.

\section{Apparatus}

An Analytik Jena cold vapor generation high resolution continuum source atomic absorption spectroscopy (model: contrAA 700) was used for the determination of $\mathrm{Hg}^{+2}$ in the samples. The optimized default conditions of this instrument conformed to Aspect CS 1.5.6 software released by the company. FTIR analyses of the modified and non-modified SBA-15 were performed in a Fourier transform infrared spectroscopy (Bruker-Tensor 27). The samples $\mathrm{pH}$ values were measured by a Metrohm pH-meter (model: 713, Herisau, Switzerland) equipped with a glass-combined electrode.

\section{Synthesis of SBA-15}

SBA-15 preparation was based on the procedure in the literature [34]. $2.0 \mathrm{~g}$ of triblock copolymer P123 $\left(\mathrm{EO}_{20} \mathrm{PO}_{70} \mathrm{EO}_{20}\right)$ was dissolved in $60.0 \mathrm{~g}$ of $2 \mathrm{M}$ Hydrochloric acid $(\mathrm{HCl})$ aqueous solution stirred at $40^{\circ} \mathrm{C}$. Then $4.3 \mathrm{~g}$ of Tetraethylorthosilicate (TEOS) was added to the homogeneous solution and stirred at this temperature for $24 \mathrm{~h}$. Finally, it was heated to $100^{\circ} \mathrm{C}$ and held at this temperature for $24 \mathrm{~h}$ under static conditions. The prepared sample was filtered, and then washed with water and air-dried at room temperature. The removal of the template was carried out at $550^{\circ} \mathrm{C}$ in air for $5 \mathrm{~h}$.

\section{Synthesis of 1, 3, 5 Trithiane as Modifier}

Since SBA-15 as the base adsorbent is not efficient for metal ions removal from aqueous environment, it needs modifying. One organic ligand that has the ability to form complex with $\mathrm{Hg}^{+2}$ is $1,3,5$ Trithiane which was previously reported by research in literature [35]. This organic compound (Figure 1) as modifier ligand was prepared based on the procedure in literature [36]. A mixture of $32.6 \mathrm{~g}$ of Formaldehyde solution $\% 36(\mathrm{w} / \mathrm{w})$ and $70 \mathrm{cc}$ of concentrated Hydrochloric acid were used and then Hydrogen sulfide passed through the solution until no more precipitate was formed. In order to facilitate the process, the accumulated mass of crystals was removed by filtration from time to time. Afterward, the product was purified by the inverted filtration method.

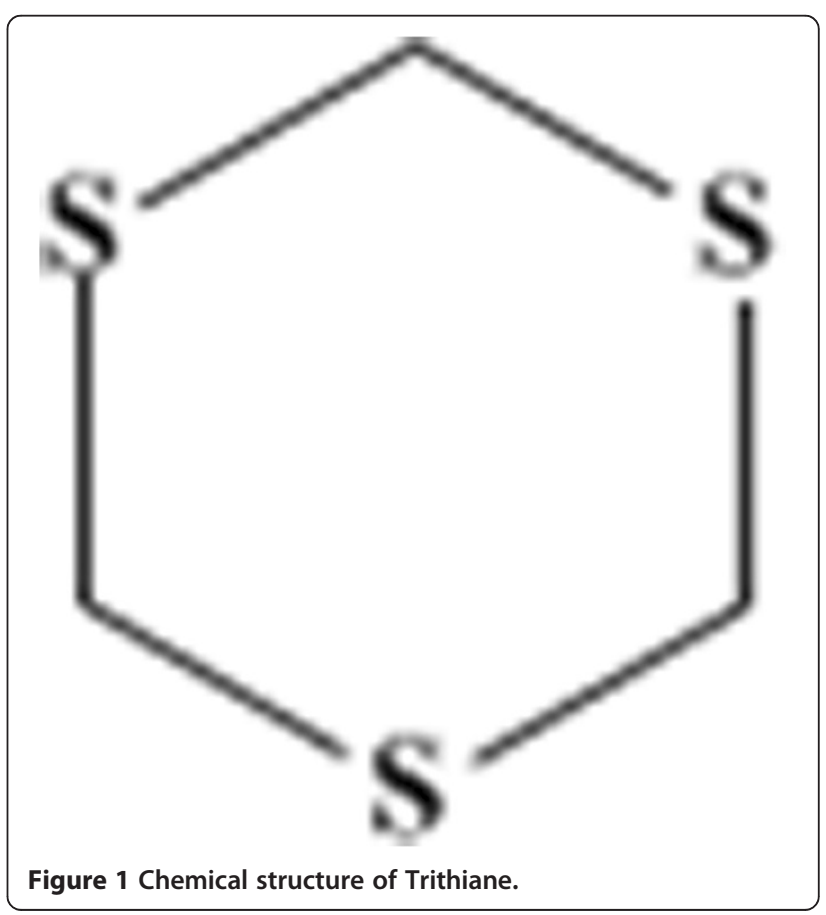




\section{Modification of SBA -15}

Modification of the prepared SBA-15 was performed by dissolving $60 \mathrm{mg}$ of Trithiane in adequate amount of Acetonitrile and adding $40 \mathrm{mg}$ of SBA- 15 and mixing for $15 \mathrm{~min}$. Next, the solution was filtered and the solid phase as the functionalized product was exposed to atmosphere and used as a new sorbent for this research.

\section{Metal adsorption experiments}

The general procedure for removal of $\mathrm{Hg}^{+2}$ by the modified SBA-15 was as follows: A batch system was employed for the removal of $\mathrm{Hg}^{+2}$ and removing was performed in a beaker containing $10 \mathrm{~mL}\left(10 \mathrm{mg} \mathrm{L}{ }^{-1}\right) \mathrm{Hg}^{+2}$ solutions. About $10 \mathrm{mg}$ modified SBA-15 was added to the solution. Then the mixture was stirred for $10 \mathrm{~min}$ to remove $\mathrm{Hg}^{+2}$ from the solution. Finally, filtration was performed and $\mathrm{Hg}^{+2}$ concentrations were determined by cold vapor generation high resolution continuum source atomic absorption spectroscopy (model: contrAA 700).

\section{Results and discussion}

SBA-15 modification seems essential through suitable ligand because this mesoporous adsorbent has a major problem removing $\mathrm{Hg}^{+2}$ from aqueous environment selectively and efficiently. Previous studies [35] indicated that 1, 3, 5 Trithiane as organic ligand has an efficient interaction with $\mathrm{Hg}^{+2}$. Hence, it was used in the modification of SBA-15 for the removal of $\mathrm{Hg}^{+2}$. The preliminary experiments showed that the removal of $\mathrm{Hg}^{+2}$ ions by non-modified and modified SBA- 15 was obviously different and the former cannot remove $\mathrm{Hg}^{+2}$ quantitatively.

\section{FTIR analysis}

For the characterization of the modified SBA-15, infrared spectrum was recorded on Bruker-Tensor 27 spectrophotometer in the region $400-4000 \mathrm{~cm}^{-1}$ using spectra quality $\mathrm{KBr}$ powder. According to Figure 2 the distinguished band at $1508 \mathrm{~cm}^{-1}$ can be assigned to Trithiane.

\section{Effect of Modified Ratio (Ligand / SBA)}

Modification ratio between ligand and adsorbent shown in this research as (Ligand / SBA-15) is one of the parameters affecting the prepared efficient modified adsorbent. In this study, mesoporous silica has been modified by Trithiane ligand by 3 modification ratios as $0.5,1$ and $1.5(\mathrm{w} / \mathrm{w})$. Then all the modified adsorbents were tested for removing $\mathrm{Hg}^{+2}$ from the samples. The results showed that the adsorbent modified by 1.5 (Ligand/SBA-15 w/w) has the maximum percentage of $\mathrm{Hg}^{+2}$ removal from the samples compared to the other two modification ratios. According to the obtained results, higher modification ratios were not studied in this research because the modified adsorbent has to be economical. On the other hand, the $\mathrm{Hg}^{+2}$ removal process revealed that by raising the modification ratio from 0.5 to 1 and 1 to 1.5 , the percentage of removal increased slightly. Therefore, in the subsequent experiments we used 1.5 (Ligand / SBA-15 w/w) modification ratio.

\section{Effect of $\mathrm{pH}$}

The aqueous samples $\mathrm{pH}$ adjustment is one of the major parameters in order to obtain efficient removal of toxic metal ions by specific adsorbents such as modified mesoporous silica. Hence, in this research the

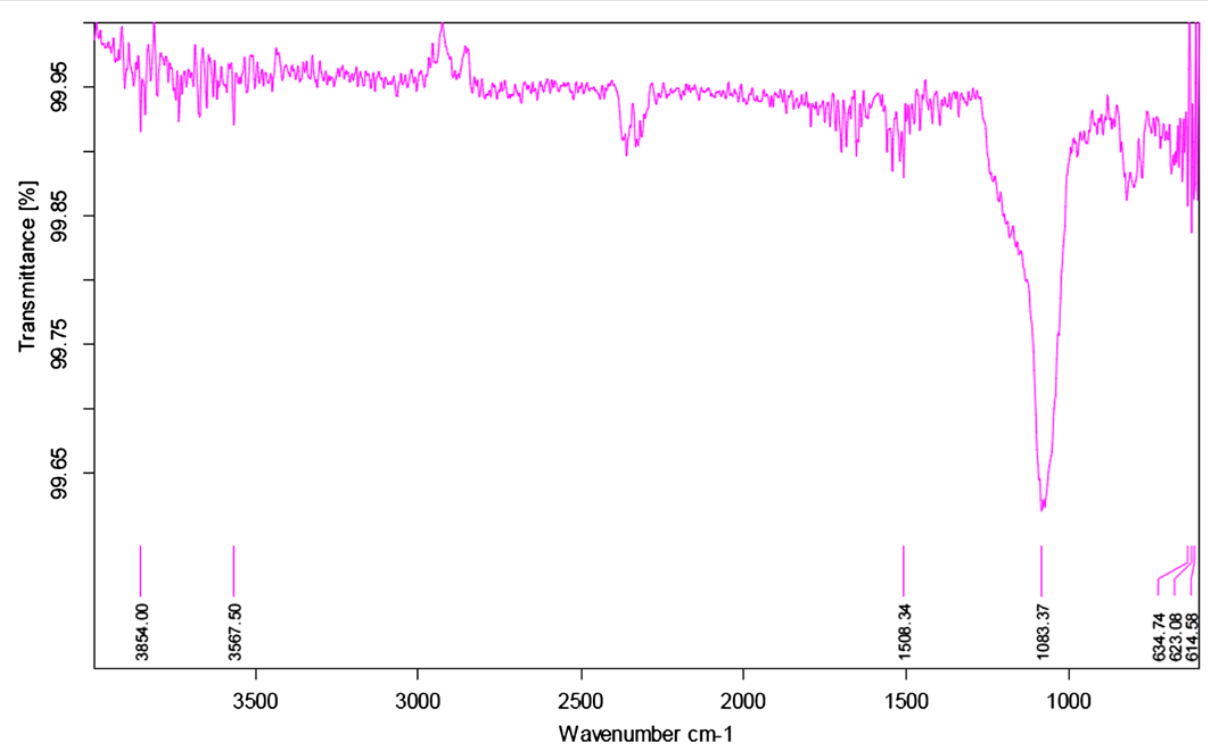

Figure 2 FTIR spectrum of modified SBA-15. 


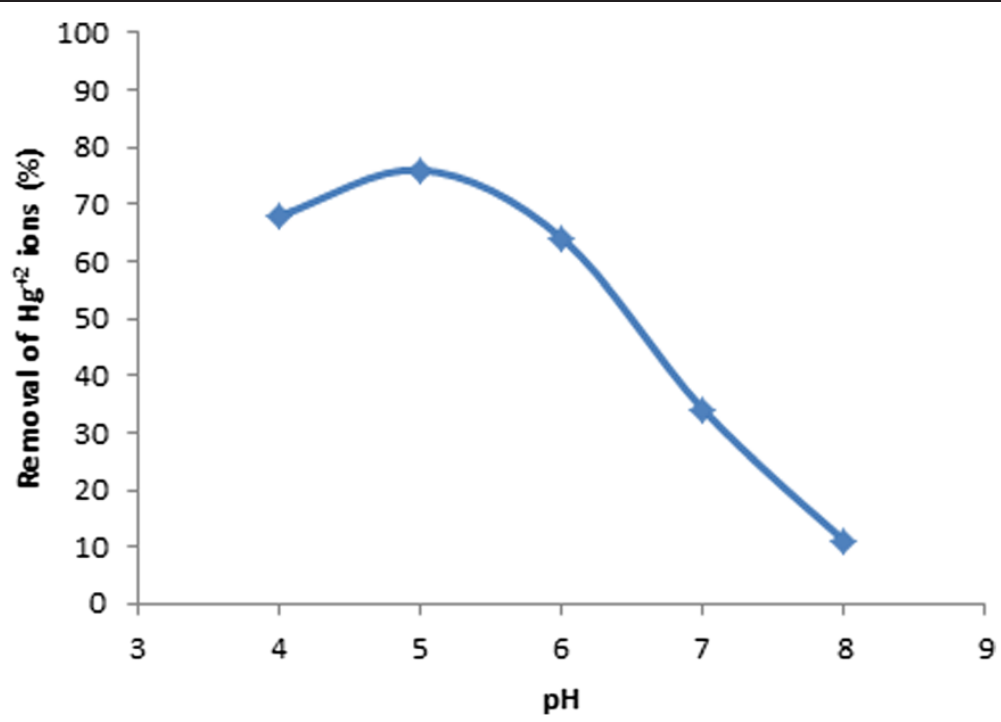

Figure 3 Effect of $\mathrm{pH}$ on the removal of $\mathrm{Hg}^{+2}$.

effect of $\mathrm{pH}$ on the removal of $\mathrm{Hg}^{+2}$ ions with modified adsorbent was studied at different $\mathrm{pH}$ values ranging from 4.0 to 8.0. As shown in Figure 3, the percentage of $\mathrm{Hg}^{+2}$ ions adsorption increased significantly between $\mathrm{pH} 4.0-5.0$ and then at $\mathrm{pH}$ higher than 5.0 decreased extremely. In $\mathrm{pH}$ values higher than 8.0, modified mesoporous silica may be hydrolyzed in alkali solutions due to the breaking of the $\mathrm{Si}-\mathrm{O}-\mathrm{Si}$ bonds by hydroxide ions attack so this range of $\mathrm{pH}$ was not studied. Also, $\mathrm{pH}$ values lower than 4.0, were not studied in this research because this range due to decreasing $\mathrm{pH}$ value causes the ligand to be surrounded by $\mathrm{H}^{+}$ions and prevents $\mathrm{Hg}^{+2}$ from reaching the ligand to form complexes for its removal from the environment. Therefore, $\mathrm{pH}$ value of the sample solutions was adjusted at 5.0 in the subsequent experiments.

\section{Effect of Weight of Adsorbent}

The optimum amount of the modified SBA- 15 for maximum removal of $\mathrm{Hg}^{+2}$ was investigated by testing different amounts of modified sorbent $(1,2,5,10,15,30$ and $45 \mathrm{mg}$ ) for $\mathrm{Hg}^{+2}$ uptake from the samples. As can be seen from Figure 4 in which the results are given, by raising the sorbent amount from 1 to $15 \mathrm{mg}$ the percentage of $\mathrm{Hg}^{+2}$ removal increased significantly and in the range of 15 to $45 \mathrm{mg}$ the percentage of removal was almost constant. Hence, in the experiments $15.0 \mathrm{mg}$ of modified SBA-15 was used thereafter.

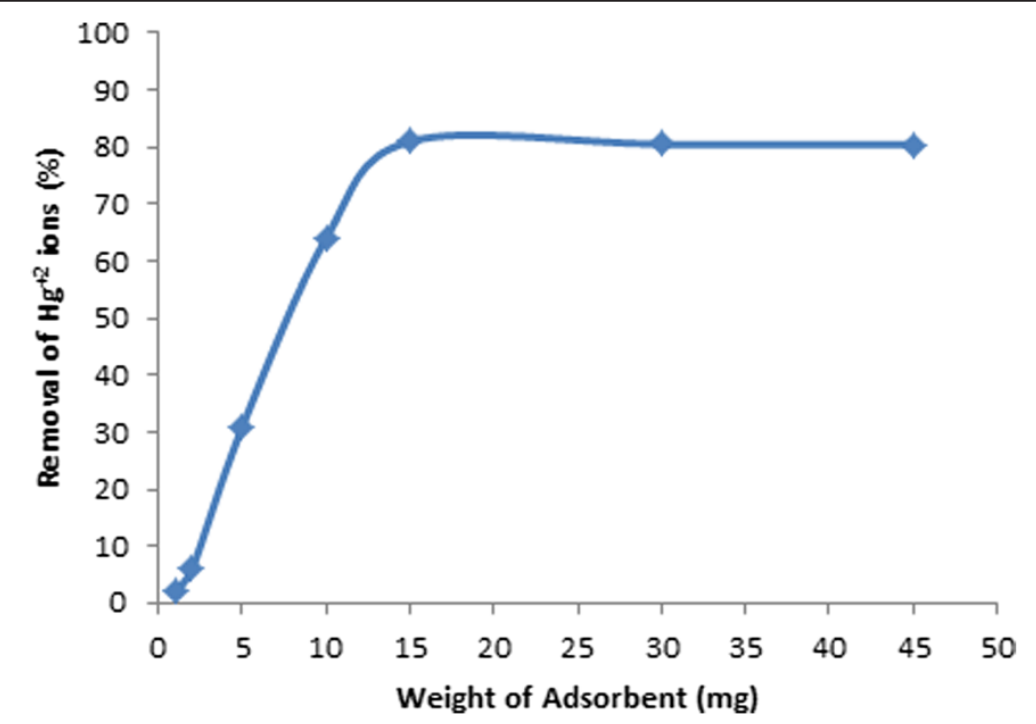

Figure 4 Effect of amount of adsorbent on the removal of $\mathrm{Hg}^{+2}$. 


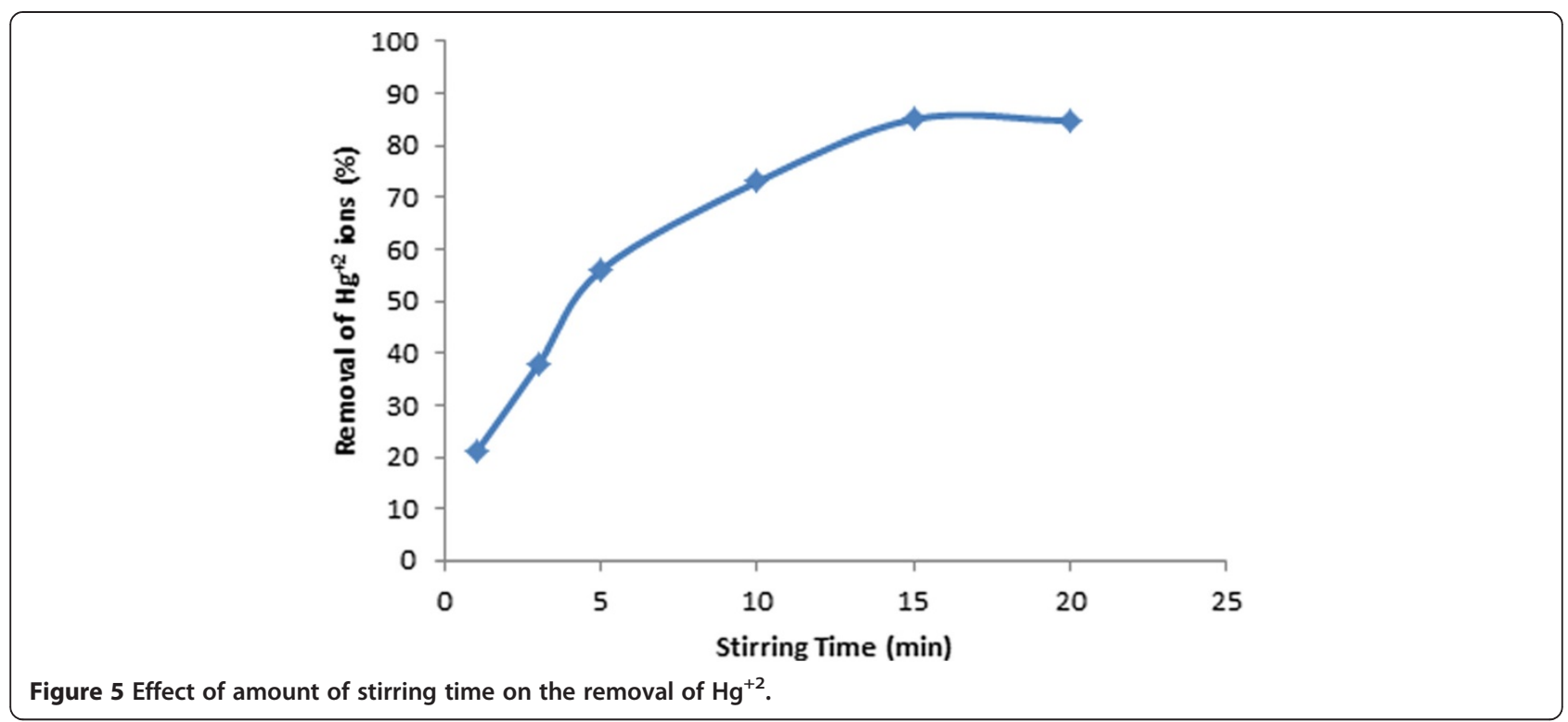

\section{Effect of the stirring time on removal yield}

The effect of stirring time on $\mathrm{Hg}^{+2}$ ions removal was investigated by performing a series of removal experiments with the same conditions and at several times $(1,3,5$, $10,15$ and $20 \mathrm{~min})$. According to the results shown in Figure $5, \mathrm{Hg}^{+2}$ removal up to $15 \mathrm{~min}$ increased and then was nearly constant. Therefore, the 15 -min stirring time was used afterward.

\section{Capacity of the modified SBA-15}

The adsorbent capacity is an important parameter in adsorption processes because it determines how much adsorbent is required to quantitatively remove a specific amount of metal ions from the solutions [37]. Thus, the adsorption capacity of $\mathrm{Hg}^{+2}$ per unit weight of the modified adsorbent at time $\mathbf{t}, \mathbf{q}_{\mathbf{t}}\left(\mathrm{mg} \mathrm{g}^{-1}\right)$, was calculated from the mass balance:

$$
q_{t}=\frac{\left(C_{0}-C_{t}\right) \times V}{\mathrm{~m}}
$$

Where $\mathbf{C}_{\mathbf{0}}\left(\mathrm{mg} \mathrm{L}^{-1}\right)$ is the initial concentration of $\mathrm{Hg}^{+2}$ and $\mathbf{C}_{\mathbf{t}}\left(\mathrm{mg} \mathrm{L}^{-1}\right)$ is $\mathrm{Hg}^{+2}$ concentration at time t. $\mathbf{V}$ is the volume of $\mathrm{Hg}^{+2}$ solutions and $\mathbf{m}$ is the mass of the modified mesoporous. The capacity of the modified adsorbent was found to be $10.6 \mathrm{mg}$ of $\mathrm{Hg}^{+2} / \mathrm{g}$ modified SBA-15.

\section{Conclusion}

In the present research, new and effective modified mesoporous silica was prepared and tested in batch mode for $\mathrm{Hg}^{+2}$ removal from the aqueous samples. The results demonstrated a successful application of modified SBA-15 for the effective removal of $\mathrm{Hg}^{+2}$ as a rapid and easy method. Maximum percentage of removal happened at $\mathrm{pH}$ equal to 5.0, 15-min stirring time and using $15 \mathrm{mg}$ of modified adsorbent. As adsorbents are used in wastewater treatment plants, the preparation of an applicable form of adsorbent such as an adsorption column and the determination of its effective parameters proves necessary so the authors will focus on this target in the future.

\section{Competing interests}

The authors declare that they have no competing interests.

\section{Authors' contributions}

This research is a part of the thesis by MEB who prepared the literature survey and performed the experiments. NM and HR participated in the design of the study, data analysis, and manuscript preparation. GRNB was the advisor. All the authors have read and approved the final manuscript.

\section{Acknowledgment}

The authors acknowledge the financial and scientific support provided by the Center of excellence in electrochemistry and Graduate faculty of Environment at the University of Tehran.

\section{Author details}

${ }^{1}$ Department of Environmental Engineering, Graduate Faculty of Environment, University of Tehran, Tehran, Iran. ${ }^{2}$ Department of Chemical Engineering, Faculty of Engineering, University of Tehran, Tehran, Iran.

Received: 8 February 2014 Accepted: 17 June 2014 Published: 25 June 2014

\section{References}

1. Rostamian R, Najafi M, Rafati AA: Synthesis and characterization of thiol-functionalized silica nano hollow sphere as a novel adsorbent for removal of poisonous heavy metal ions from water: Kinetics, isotherms and error analysis. Chem Eng J 2011, 171:1004-1011.

2. Aguado J, Arsuaga JM, Arencibia A, Lindo M, Gascon V: Aqueous heavy metals removal by adsorption on amine-functionalized mesoporous silica. J Hazard Mater 2009, 163:213-221.

3. Boening DW: Ecological effects, transport, and fate of mercury: a general review. Chemosphere 2000, 40(12):1335-1351.

4. Evangelista SM, Deoliveira E, Castro GR, Zara LF, Prado AGS: Hexagonal mesoporous silica modified with 2-mercaptothiazoline for removing mercury from water solution. Surf Sci 2007, 601:2194-2202. 
5. Esmaeili Bidhendi M, Karbassi AR, Baghvand A, Saeedi M, Pejman AH: Potential of natural bed soil in adsorption of heavy metals in industrial waste landfill. Int J Environ Sci Tech 2010, 7(3):545-552.

6. Lee $B, \operatorname{Kim} Y$, Lee $H$, Yi J: Synthesis of functionalized porous via templating method as heavy metal ion adsorbents: the introduction of surface hydrophilicity onto the surface of adsorbents. Micropor Mesopor Mater 2001, 50:77-90.

7. Nabi SA, Shahadat M, Bushra R, Shalla AH, Ahmed F: Development of composite ion-exchange adsorbent for pollutants removal from environmental wastes. Chem Eng J 2010, 165:405-412.

8. Najafi M, Rostamian R, Rafati AA: Chemically modified silica gel with thiol group as an adsorbent for retention of some toxic soft metal ions from water and industrial effluent. Chem Eng J 2011, 168:426-432.

9. Huuha TS, Kurniawan TA, Sillanpaa MET: Removal of silicon from pulping whitewater using integrated treatment of chemical precipitation and evaporation. Chem Eng J 2010, 158:584-592

10. Quintanilla DP, Hierro ID, Fajardo M, Sierra I: 2-Mercaptothiazoline modified mesoporous silica for mercury removal from aqueous media. J Hazard Mater 2006, B134:245-256.

11. Babel S, Kurniawan TA: Low-cost adsorbents for heavy metals uptake from contaminated water: a review. J Hazard Mater 2003, 97:219-243.

12. Mahmoud ME, Osman MM, Hafez OF, Hegazi AH, Elmelegy E: Removal and preconcentration of lead (II) and other heavy metals from water by alumina adsorbents developed by surface-adsorbed-dithizone. Desalination 2010, 251:123-130.

13. Mahmoud ME, Hafez OF, Alrefaay A, Osman MM: Performance evaluation of hybrid inorganic/organic adsorbents in removal and preconcentration of heavy metals from drinking and industrial waste water. Desalination 2010, 253:9-15.

14. Mahmoud ME, Kenawy IMM, Hafez MAH, Lashein RR: Removal, preconcentration and determination of trace heavy metal ions in water samples by AAS via chemically modified silica gel N-(1-carboxy-6-hydroxy) benzylidenepropylamine ion exchanger. Desalination 2010, 250:62-70.

15. Burham N: Separation and pre concentration system for lead and cadmium determination in natural samples using 2aminoacetylthiophenol modified polyurethane foam. Desalination 2009 249:1199-1205.

16. Ciftci $H$, Yalcin $H$, Eren E, Olcucu A, Sekerci M: Enrichment and determination of $\mathrm{Ni}^{2+}$ ions in water samples with a diamino-4-(4-nitro-phenylazo)-1H-pyrazole (PDANP) by using FAAS. Desalination 2010, 256:48-53.

17. Chakravarty P, Sen Sarma N, Sarma HP: Removal of lead (II) from aqueous solution using heartwood of Areca catechu powder. Desalination 2010, 256:16-21.

18. Lei B, Li B, Zhang HR, Lu SZ, Zheng ZH, Li WL, Wang Y: Mesostructured Silica Chemically Doped with Rull as a Superior Optical Oxygen Sensor. Adv Funct Mater 2006, 16(14):1883-1891.

19. Perez-Quintanilla D, Sanchez A, Del Hierro I, Fajardo M, Sierra I: Preparation of 2-mercaptobenzenothiazole-derivatived mesoporous silica and of $\mathrm{Hg}$ (II) from aqueous solution. J Environ Monit 2006, 8:214-222.

20. Perez-Quintanilla D, Sanchez A, Del Hierro I, Fajardo M, Sierra I: Preconcentration of $\mathrm{Zn}$ (II) in water samples using a new hybrid SBA-15based material. J Hazard Mater 2009, 166:1449-1458.

21. Perez-Quintanilla D, Sanchez A, Del Hierro I, Fajardo M, Sierra I: Solid phase extraction of $\mathrm{Pb}(\mathrm{II})$ in water samples using a new hybrid inorganic-organic mesoporous silica prior to its determination by FAAS. Microchim Acta 2009, 165:291-298.

22. Kang T, Park Y, Choi K, Sang Leec J, Yi J: Ordered mesoporous silica (SBA-15) derivatized with imidazole-containing functionalities as a selective adsorbent of precious metal ions. J Mater Chem 2004, 14:1043-1049.

23. Ganjali MR, Hajiaghababaei L, Badiei AR, Saberyan K, Salavati-Niasari M, Ziarani GM, Behbahani SMR: A novel method for fast enrichment and monitoring of hexavalent and trivalent chromium at the PPT level with modified silica MCM-41 and its determination by inductively coupled plasm optical emission spectrometry. Quim Nova 2006, 29:440-443.

24. Ganjali MR, Hajiaghababaei L, Badiei AR, Ziarani GM, Tarlani A: Novel method for the fast preconcentration and monitoring of a ppt level of lead and copper with a modified hexagonal mesoporous silica compound and inductively coupled plasma atomic emission spectrometry. Anal Sci 2004, 20:725-729.
25. Ju YH, Webb OF, Dai S, Lin JS, Barnes CE: Synthesis and characterization of ordered mesoporous anion-exchange inorganic hybrid resins for radionuclide separation. Ind Eng Chem Res 2000, 39:550-553.

26. Ho KY, Mckay G, Yeung KL: Selective adsorbents from ordered mesoporous silica. Langmuir 2003, 19:3019-3024.

27. Lim MH, Stein A: Comparative studies of grafting and direct syntheses of inorganic-organic hybrid mesoporous materials. Chem Mater 1999, 11:3285-3295.

28. Lee B, Bao LL, Im HJ, Dai S, Hagaman EW, Lin JS: Synthesis and characterization of organic-inorganic hybrid mesoporous anionexchange resin for perrhenate ( $\mathrm{ReO} 4-$ ) anion adsorption. Langmuir 2003, 19:4246-4252.

29. Fryxell GE, Liu J, Hauser TA, Nie Z, Ferris KF, Mattigod S, Gong M, Hallen RT: Design and synthesis of selective mesoporous anion traps. Chem Mater 1999, 11:2148-2154.

30. Hajiaghababaei L, Badiei A, Ganjali MR, Heydari S, Khaniani Y, Mohammadi Ziarani G: Highly efficient removal and preconcentration of lead and cadmium cations from water and wastewater samples using ethylenediamine functionalized SBA-15. Desalination 2011, 266:182-187.

31. Zhao D, Huo Q, Feng J, Chmelka BF, Stucky GD: Nonionic triblock and star diblock copolymer and ologomeric surfactant syntheses of highly ordered, hydrothermally stable, mesoporous silica structures. J Am Chem Soc 1998, 120:6024-6037

32. Badiei A, Norouzi P, Tousi F: Study of electrochemical behavior and adsorption mechanism of $\left[\mathrm{Co}(\mathrm{en}){ }_{2} \mathrm{C}_{12}\right]+$ on mesoporous modified carbon paste electrode. Eur J Sci Res 2005, 12:39-45.

33. Badiei A, Bonneviot L, Crowther N, Mohammadi Ziarani G: Surface tailoring control in micelle templated silica. J Organomet Chem 2006, 691:5923-5931.

34. Murty DSR, Chakrapani G: Preconcentration of rare earth elements on activated carbon and its application to groundwater and sea-water analysis. J Anal At Spectrom 1996, 11:815-820.

35. Ercan Ö, Aydınb A: Removal of Mercury, Antimony, Cadmium and Lead from Aqueous Solution using 1,3,5-Trithiane as an Adsorbent. J Braz Chem Soc 2013, 24(5):865-872.

36. Organic Syntheses. In Coll. Vol. 2, p.610 (1943); Vol. 16, p.81 (1936). [http://www.orgsyn.org/Content/pdfs/procedures/CV2P0610.pdf]

37. Dev K, Rao GN: Preparation and analytical properties of a chelating resin containing bicine groups. Talanta 1995, 42:591-596.

\section{doi:10.1186/2052-336X-12-100}

Cite this article as: Esmaeili Bidhendi et al: Modified Mesoporous Silica (SBA-15) with Trithiane as a new effective adsorbent for mercury ions removal from aqueous environment. Journal of Environmental Health Science \& Engineering 2014 12:100.

\section{Submit your next manuscript to BioMed Central and take full advantage of:}

- Convenient online submission

- Thorough peer review

- No space constraints or color figure charges

- Immediate publication on acceptance

- Inclusion in PubMed, CAS, Scopus and Google Scholar

- Research which is freely available for redistribution 